\title{
Leukotriene D4 Measurement
}

National Cancer Institute

\section{Source}

National Cancer Institute. Leukotriene D4 Measurement. NCI Thesaurus. Code C103414.

The determination of the amount of the leukotriene D4 in a sample. 